\title{
A Mathematical Model of the Smoke Layer Evolution in Compartment Fires
}

\author{
V. Bennardo* and N. Inzaghi \\ Corpo Nazionale dei Vigili del Fuoco, Corso Regina Margherita 330, 10143 Torino, Italy
}

\begin{abstract}
The paper describes a mathematical model suitable to calculate the evolution in time of the smoke layer thickness and temperature during a compartment fire, and to estimate the time required to fill the compartment as a function of the thermophysical properties of the flame and of the compartment geometry. The model also allows one to calculate the volumetric flow rate and the enthalpy flow of the smoke through the openings in the building envelope, which are directly related to the environmental impact of the fire.
\end{abstract}

Keywords: Field models, compartment fire, computational fluid dynamics codes, zone models, smoke layer thickness.

\section{INTRODUCTION}

The main phenomena that can be observed macroscopically during a compartment fire consist in the formation of a layer of hot air contaminated by toxic gases and partially burnt fuel particles above a layer of pure air, in the smoke evacuation through vent openings in the building envelope, and in the dispersion of the combustion products plume in the atmosphere.

The thermo-fluid dynamic parameters relevant to the description of the event under consideration from the point of view of safety and of the environmental impact are the thickness and the temperature of the smoke layer, the fresh air layer thickness, the volumetric flow rate of smoke between the compartment and the surrounding environment, and the enthalpy flow of combustion products.

Prediction of the temporal evolution of the smoke-free fresh air layer thickness is essential in establishing procedures for firefighters operation and people evacuation; knowledge of the smoke flow rate is necessary to design ventilation systems; the enthalpy flow is important to calculate the plume height hence its dispersion in the atmosphere and the consequent environmental impact of the compartment fire.

Because generation and collection of experimental data in compartment fires is difficult and expensive, both in the case of field tests and in that of reduced-scale models, many research projects aim at developing mathematical models of growing complexity, in order to obtain more detailed information about the event under consideration. In particular, mathematical models to simulate the growth process of the smoke layer generated by fires can be sorted into two families: zone models and field models.

Zone models are lumped parameter models, which are based on the identification of regions with a uniform distri-

*Address correspondence to this author at the Corpo Nazionale dei Vigili del Fuoco, Corso Regina Margherita 330, 10143 Torino, Italy; Tel: +39 01174221; Fax: +39 0117422500;

E-mail: vincenzo.bennardo@vvf.to.it bution of thermo-fluid dynamic parameters within the volume where the fire has occurred, and assuming negligible mass transport from one of these regions to another. This leads to the formulation of ordinary differential equations which can be solved with appropriate analytical or numerical methods, and return the temporal evolution of the relevant thermo-fluid dynamics variables. Formal simplicity, obtained at the expenses of an accurate description of the process under consideration, is the feature that makes zone models very popular in engineering practice to design and test automatic fire detection systems and ventilation of buildings [1-3].

Field models are distributed parameter models where the fire development region is divided into a large number of interconnected cells or elements (computational grid), and physical phenomena are modeled by discretized partial differential equations to solve the turbulent flow of an incompressible fluid using the finite volumes or the finite elements method. The discrete model consists of a system of nonlinear algebraic equations, coupled through appropriate numerical algorithms. Field models allow, within the limits of existing closure relationships for combustion and turbulence, a detailed description of the three-dimensional characteristics of flows caused by fire, as well as the evolution of smoke layer generated in geometric domains of arbitrary form and under different flow conditions [4].

The information obtained from the solution of field models can be used to optimize the design of fire mitigation systems and of ventilation, both from the point of view of fire safety and from that of energy saving. However, despite many computational fluid dynamics codes implementing these models are commercially available, in engineering practice their use is somewhat limited by the lack of suitable machines, and the long execution time [5].

The mathematical model presented in this work, which belongs to the family of zone models, was constructed using the basic principles of thermodynamics and appropriate semi-empirical correlations to model the growth process of flames and smoke generation. The mode allows one to simulate the temporal evolution of the smoke layer thickness and 
temperature, and to estimate the combustion products flow rate discharged from the building envelope into the surrounding environment and the environmental impact of fire by calculating the elevation of the plume. The results are compared with those obtained using other zone models available in the open literature $[6,7]$.

\section{MATHEMATICAL MODEL}

A schematic picture of the compartment geometry is shown in Fig. 1. The model of the smoke layer growth was derived after introducing the following assumptions:

- Existence of a layer of air contaminated by smoke, characterized by a homogeneous distribution of temperature, stratified above a layer of pure air;

- Negligible mass transport between the two layers;

- The driving force can be the density difference between smoke and air environment, or a constant air flow is generated by a fan.

A detailed analysis of two-layer models [2] shows that they give accurate predictions under the following flow conditions:

- No recirculation of air between the two layers;

- Uniform distribution of openings and of the auxiliary ventilation air intakes over the building envelope.

The former condition occurs typically during the initial stages of a compartment fire, when the flame size is small relative to the size of the building envelope, and holds until recirculation and mixing of combustion products begins to influence the flame growth. The latter condition, which is equivalent to neglect the influence of local velocity profiles near openings on the global distribution of the smoke layer, is highly dependent on the topology of the environment where the fire develops.

The smoke layer growth model is based on the conservation equations for mass, mechanical energy, and thermal energy, and is completed by semi-empirical closure relation- ships to estimate: (i) the heat release rate, as a function of time; (ii) the smoke mass flow rate, as a function of the energetic and fluid dynamic features of the flame; (iii) the maximum height reached by the smoke plue in the atmosphere.

The mass conservation equation can be written as:

$\frac{d M_{s}}{d t}=\dot{m}_{s}-\rho_{s} \dot{Q}$

with the obvious initial condition $M_{s}(0)=0$. In Eq. (1), $M_{s}$ is the smoke mass in the compartment, $\dot{m}_{s}$ is the smoke generation rate, $\rho_{s}$ is the smoke density, and $\dot{Q}$ is the volumetric flow rate through the openings of the building envelope. This equation allows one to determine the position of the airsmoke interface as:

$H_{a}=H-\frac{M_{s}}{S \rho_{s}}$

where $H_{a}$ is the height of the interface, $H$ is the compartment height, and $\mathrm{S}$ the compartment surface. The smoke density, $\rho_{s}$, and that of ambient air, $\rho_{a}$, are related by the ideal gas equation:

$\rho_{s}=\frac{T_{a}}{T_{s}} \rho_{a}$

where $T_{a}$ and $T_{s}$ are the ambient air and the smoke temperatures, respectively.

The conservation equation for thermal energy can be expressed in the form:

$\frac{d T_{s}(t)}{d t}=\frac{q_{c}-\dot{Q} \rho_{s} c_{p}\left(T_{s}-T_{a}\right)-h\left[S+P\left(H-H_{a}\right)\right]\left(T_{s}-T_{a}\right)}{\rho_{s} c_{p}\left[S\left(H-H_{a}\right)+H_{a} A_{s}\right]}$

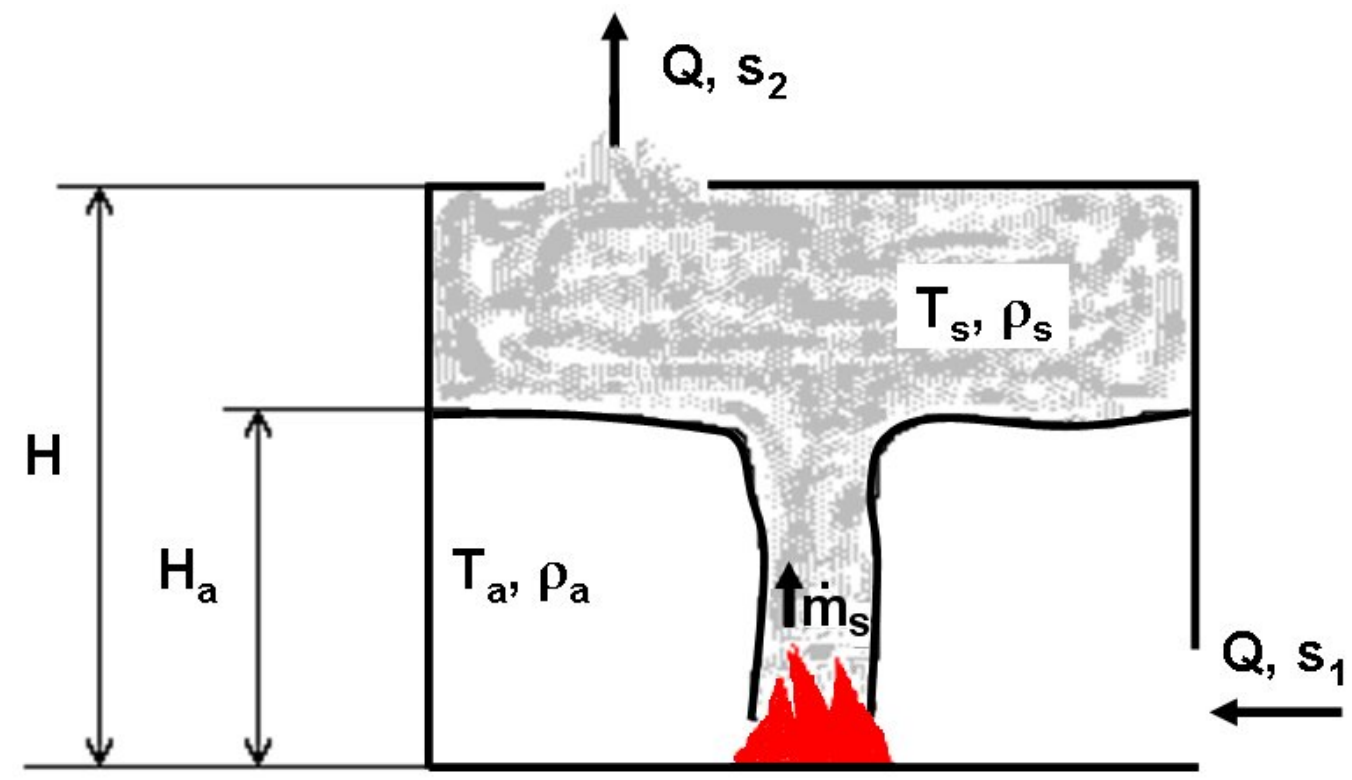

Fig. (1). Schematic representation of the compartment fire and its main geometric parameters. 
with the initial condition $T_{s}(0)=T_{a}$. In Eq. (4), $q_{c}$ is the heat rate transferred by convection from the flame to the smoke layer, $h$ is the overall heat transfer coefficient with the compartment walls, $c_{p}$ is the specific heat of air at constant pressure, $P$ is the envelope perimeter, $A_{s}$ is the crosssectional area of the smoke plume just above the flame.

The volumetric mass flow rate through the openings of the building envelopecan be calculated by using Bernoulli's equation:

$$
\left(H-H_{a}\right)\left(\rho_{s}-\rho_{a}\right)=\frac{\dot{Q}^{2}}{2 g}\left(\frac{c_{1}}{s_{1}^{2}}\left(\frac{\rho_{f}}{\rho_{a}}\right)^{2}+\frac{c_{2}}{s_{2}^{2}}\right)
$$

where $c_{1}$ and $c_{2}$ are the pressure drop coefficients for inlets and outlets, respectively, $s_{1}$ and $s_{2}$ the corresponding crosssectional areas, and $g$ is gravity acceleration.

The various terms which appear in Eqs. (2-5) can be expressed in terms of semi-empirical correlations which can be found in the technical literature. In particular, the mathematical model of the flame includes a relationship to calculate the heat release rate of the flame, $q_{i}$, as a function of time:

$$
q_{i}(t)= \begin{cases}\alpha t^{2} \exp \left[-\left(\frac{t}{t^{*}}\right)^{2}\right] & t<t^{*} \\ q_{\infty} & t \geq t^{*}\end{cases}
$$

where $t^{*}=\sqrt{\frac{q_{\infty} e}{\alpha}}$ is the characteristic time of the flame, $\alpha$ is an empirical flame growth coefficient, $t$ is time, $q_{\infty}$ is the maximum thermal power generated by the flame and $e$ is Napier's number. The thermal power actually transferred to the smoke layer is determined through another empirical coefficient, $\alpha_{c}$, which depends both on the fluel characteristics and on the shape of the flame:

$q_{c}=\alpha_{c} q_{i}$

The coefficients $\alpha_{c}$ and $\alpha$ may vary within the following ranges:

$$
0.001<\alpha<1
$$$$
0.6<\alpha_{c}<0.9
$$

Fig. 2 shows typical heat release rate curves with respect to time, for different maximum thermal power.

The mathematical model of the smoke plume includes both closure relationships to determine the smoke flow rate generated by combustion of different materials (fuels) and for different sizes of the fire, and closure relationships to estimate the maximum plume height in the atmosphere. The smoke generation rate of liquid pool fires can be determined using the following correlations [8-11]:

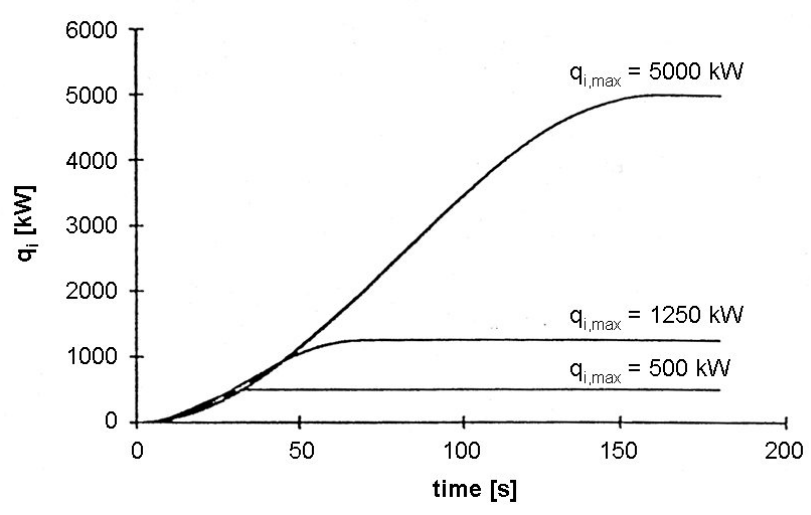

Fig. (2). Heat release rate as a function of time, for fires of different values of the maximum power.

$\dot{m}_{s}=0.071 q_{c}^{1 / 3}\left(H_{a}-z_{0}\right)^{5 / 3}\left[1+0.026 q_{c}^{2 / 3}\left(H_{a}-z_{0}\right)^{-5 / 3}\right]$

for $H_{a}>z_{1}$

and

$\dot{m}_{s}=\frac{0.0054 q_{c} H_{a}}{0.166 q_{c}^{2 / 5}+z_{0}} \quad$ for $\quad H_{a} \leq z_{1}$

where $z_{1}$ and $z_{0}$ represent respectively the transition height and the virtual origin of the plume; for a flame of characteristic diameter $D$ generating a plume of the same size, these are given by:

$$
\begin{aligned}
& z_{0}=-1.02 D+0.083 q_{i}^{2 / 5} \\
& z_{1}=z_{0}+0.166 q_{c}^{2 / 5}
\end{aligned}
$$

If the flame height, $\mathrm{L}$, is related to its diameter through the following expression:

$$
L=29\left(\frac{D}{2}\right)^{0.7}\left(\frac{10^{-3} h_{c}}{c_{p c}\left(T_{c b}-T_{a}\right)+h_{v}}\right)^{0.6}
$$

where $h_{c}$ and $h_{v}$, indicate the combustion heat $(\mathrm{J} / \mathrm{kg})$ and the latent heat of vaporization $(\mathrm{J} / \mathrm{kg})$, respectively, and $\mathrm{c}_{\mathrm{pc}}$ the specific heat of the fuel $(\mathrm{J} / \mathrm{kgK})$, the virtual origin of the plume is given by:

$z_{0}=-0.147 q_{i}^{2 / 5}+L$

The smoke generation rate in case of solid fuels can be estimated using the same correlations for liquid pool fires, setting the height of the virtual origin of the plume equal to zero, so that Eqs. (9) and (10) become:

$\dot{m}_{s}=0.071 q_{c}^{1 / 3} H_{a}^{5 / 3}+1.846 \times 10^{-3} q_{c}$ for $H_{a}>z_{1}$

and

$\dot{m}_{s}=0.0325 q_{c}^{3 / 5} H_{a}$ for $H_{a} \leq z_{1}$

with

$z_{1}=0.166 q_{c}^{2 / 5}$ 
If the solid fuel is arranged in a stack, an approximate estimation of the smoke generation rate is given by:

$\dot{m}_{s}=0.021 q_{c}^{1 / 3} H_{a}^{5 / 3}$

The flow rate generated by large fires can be determined using the relationship proposed by Thomas [12], which requires knowledge of the flame perimeter, $p$, instead of the heat release rate:

$\dot{m}_{s}=0.188 p H_{a}^{3 / 2}$

Another important parameter, which is also necessary to assess the environmental impact of the fire, is the maximum height of the plume generated by the smoke that leaves through the openings in the building envelope. This quantity can be estimated using a relationship proposed by Briggs [13], suitable for high-enthalpy plumes:

$\Delta H_{B}=0.53 q_{h}^{1 / 3} X^{2 / 3} u^{-1}$

where $q_{h}$ is the enthalpy rate of the smoke $(\mathrm{kcal} / \mathrm{s}), \mathrm{X}$ is the leeward distance from the source $(\mathrm{m}), \mathrm{u}$ is the wind velocity $(\mathrm{m} / \mathrm{s})$. The parameter defined by Eq. (20) is a fundamental input of Gaussian dispersion models for the dispersion of smoke plumes in the atmosphere [14], which are commonly used to assess the region of influence of a fire.

The time required to completely fill the compartment with smoke, $t_{r}$, can be estimated analytically using the mass conservation equation together with one of the correlations to calculate the smoke generations rate. For example, using Eq. (19) with the approximation $\rho_{s} \approx \rho_{a}$ yields:

$-\frac{d H_{a}}{d t}=\frac{0.188 p H_{a}^{3 / 2}}{\rho_{a} S}$

which after integration becomes:

$\frac{1}{\sqrt{H_{a}}}-\frac{1}{\sqrt{H}}=A t$

where the constant $\mathrm{A}$ is defined as:

$A=\frac{0.188 p}{2 \rho_{a} S}$
If the smoke layer thickness is expressed as a fraction of the total height of the compartment, and introducing the time constant $\tau=A \frac{S}{\sqrt{H}}$, one obtains:

$\frac{H_{a}}{H}=\left(\frac{t}{\tau}+1\right)^{-2}$

Eq. (24) can be re-arranged in terms of the shape factor of the compartment, defined as $\xi=\frac{H}{\sqrt{S}}$, and of the compartment volume, $V$, so that:

$\frac{H_{a}}{H}=\left(\frac{\xi t}{\sqrt{V}}+1\right)^{-2}$

Thus, the time required to fill the compartment from a given initial moment during the fire can be calculated from the geometric parameters of the compartment and the initial thickness of the smoke layer.

\section{RESULTS}

The mathematical model outlined above, implemented as a software routine, was used to study the evolution of the smoke layer in block compartments having different aspect ratios, as detailed in Table $\mathbf{1}$, and for different characteristics of the flame. Numerical results obtained by changing the heat release rate of the flame and the inlet and outlet crosssections of the building envelope are summarised in Tables (2-4), for firs of low, medium and high intensity, respectively. In particular, the most significant parameters are the the survival time, $t_{s}$, which is defined as the time required for the smoke to reach the height of $2 \mathrm{~m}$ inside the compartment, the time required to completely fill the compartment, $t_{r}$, and the corresponding smoke temperatures, $\mathrm{T}_{\mathrm{ss}}$ and $\mathrm{T}_{\mathrm{sr}}$, respectively.

Figs. (3-11) show a detailed analysis of three geometric configurations, corresponding to the typical dimensions of a room, an industrial estate, and a road tunnel, respectively. In particular, these figures report the time evolution of the smoke layer height, of the smoke temperature, and of the smoke flow rate, for different areas of the openings in the compartment envelope.

Table 1. Geometric Parameters of Block Compartments with Dimensions a $\times \mathbf{b} \times \mathbf{c}$

\begin{tabular}{|c|c|c|c|c|c|}
\hline Case & $\mathbf{a}$ & b & c & $\xi$ & Description \\
\hline $\mathrm{B}_{2}$ & 2 & 1 & 1 & $1 / \sqrt{2}$ & hall \\
\hline $\mathrm{B}_{3}$ & 3 & 1 & 1 & $1 / \sqrt{3}$ & large hall \\
\hline $\mathrm{C}$ & 1 & 1 & 3 & 3 & staircase \\
\hline $\mathrm{D}_{3}$ & 30 & 1 & 1 & $1 / \sqrt{30}$ & tunnel \\
\hline
\end{tabular}


Table 2. Analysis of a 0.5 MW Fire in Compartments of Different Geometry

\begin{tabular}{|c|c|c|c|c|c|c|c|c|c|c|c|c|}
\hline \multicolumn{13}{|c|}{$\mathrm{Q}_{\mathrm{i}}=0.5 \mathrm{MW} \alpha=1$} \\
\hline \multicolumn{5}{|c|}{$\mathrm{s}_{1}=\mathrm{s}_{2}=0 \mathrm{~m}^{2}$} & \multicolumn{4}{|c|}{$\mathrm{s}_{1}=\mathrm{s}_{2}=10 \mathrm{~m}^{2}$} & \multicolumn{4}{|c|}{$\mathrm{s}_{1}=\mathrm{s}_{2}=20 \mathrm{~m}^{2}$} \\
\hline Case & $\mathbf{t}_{\mathbf{r}}[\mathrm{sec}]$ & $\mathbf{t}_{\mathbf{s}}[\mathrm{sec}]$ & $\mathbf{T}_{\mathbf{s r}}[\mathrm{K}]$ & $\mathbf{T}_{\mathbf{s s}}[\mathrm{K}]$ & $\mathbf{t}_{\mathbf{r}}[\mathrm{sec}]$ & $\mathbf{Q}_{\mathbf{S}}\left[\mathrm{m}^{3} / \mathrm{s}\right]$ & $\mathbf{H}_{\mathbf{a}}[\mathrm{m}]$ & $\mathbf{T}_{\mathbf{s r}}[\mathrm{K}]$ & $\mathbf{t}_{\mathbf{r}}[\mathrm{sec}]$ & $\mathbf{Q}_{\mathbf{S}}\left[\mathrm{m}^{3} / \mathrm{s}\right]$ & $\mathbf{H}_{\mathbf{a}}[\mathrm{m}]$ & $\mathbf{T}_{\mathbf{s r}}[\mathrm{K}]$ \\
\hline A & 191 & 97 & 390 & 349 & 86 & 11.21 & 6.78 & 313 & 135 & 15.13 & 8.23 & 310 \\
\hline $\mathrm{B}_{2}$ & 365 & 180 & 402 & 360 & 375 & 10.81 & 6.64 & 311 & 235 & 14.82 & 8.15 & 308 \\
\hline $\mathrm{B}_{3}$ & 536 & 260 & 409 & 366 & 452 & 10.44 & 6.54 & 309 & 280 & 14.53 & 8.08 & 307 \\
\hline $\mathrm{C}$ & 233 & 134 & 323 & 311 & 329 & 19.64 & 9.81 & 303 & 222 & 31.08 & 13.07 & 300 \\
\hline $\mathrm{D}_{1}$ & $\mathrm{n} / \mathrm{a}$ & 808 & $\mathrm{n} / \mathrm{a}$ & 384 & 780 & 8.66 & 6.25 & 303 & 883 & 13.11 & 7.68 & 302 \\
\hline
\end{tabular}

Table 3. Analysis of a 1.25 MW Fire in Compartments of Different Geometry

\begin{tabular}{|c|c|c|c|c|c|c|c|c|c|c|c|c|}
\hline \multicolumn{13}{|c|}{$\mathrm{Q}_{\mathrm{i}}=1.25 \mathrm{MW} \alpha=0.7$} \\
\hline \multicolumn{5}{|c|}{$\mathrm{s}_{1}=\mathrm{s}_{2}=0 \mathrm{~m}^{2}$} & \multicolumn{4}{|c|}{$\mathrm{s}_{1}=\mathrm{s}_{2}=10 \mathrm{~m}^{2}$} & \multicolumn{4}{|c|}{$\mathrm{s}_{1}=\mathrm{s}_{2}=20 \mathrm{~m}^{2}$} \\
\hline Case & $\mathbf{t}_{\mathbf{r}}[\mathrm{sec}]$ & $\mathbf{t}_{\mathbf{s}}[\mathrm{sec}]$ & $\mathbf{T}_{\mathbf{s r}}[\mathrm{K}]$ & $\mathbf{T}_{\text {ss }}[\mathrm{K}]$ & $\mathbf{t}_{\mathbf{r}}[\mathrm{sec}]$ & $\mathbf{Q}_{\mathbf{S}}\left[\mathrm{m}^{3} / \mathrm{s}\right]$ & $\mathbf{H}_{\mathbf{a}}[\mathrm{m}]$ & $\mathbf{T}_{\mathbf{s r}}[\mathrm{K}]$ & $\mathbf{t}_{\mathbf{r}}[\mathrm{sec}]$ & $\mathbf{Q}_{\mathbf{S}}\left[\mathrm{m}^{3} / \mathrm{s}\right]$ & $\mathbf{H}_{\mathbf{a}}[\mathrm{m}]$ & $\mathbf{T}_{\mathbf{s r}}[\mathrm{K}]$ \\
\hline $\mathrm{A}$ & 117 & 75 & 412 & 362 & 163 & 15.87 & 6.52 & 332 & 106 & 22.46 & 8.05 & 325 \\
\hline $\mathrm{B}_{2}$ & 206 & 123 & 434 & 382 & 166 & 15.21 & 6.41 & 328 & 166 & 20.97 & 7.98 & 322 \\
\hline $\mathrm{B}_{3}$ & 293 & 170 & 446 & 394 & 368 & 14.70 & 6.30 & 324 & 186 & 20.50 & 7.92 & 320 \\
\hline $\mathrm{C}$ & 143 & 99 & 331 & 317 & 311 & 27.00 & 9.58 & 312 & 229 & 42.70 & 12.89 & 307 \\
\hline $\mathrm{D}_{1}$ & 886 & 485 & 481 & 426 & 728 & 12.30 & 5.90 & 312 & 814 & 18.48 & 7.53 & 311 \\
\hline
\end{tabular}

Table 4. Analysis of a 5 MW Fire in Compartments of Different Geometry

\begin{tabular}{|c|c|c|c|c|c|c|c|c|c|c|c|c|}
\hline \multicolumn{13}{|c|}{$\mathrm{Q}_{\mathrm{i}}=5 \mathrm{MW} \alpha=0.5$} \\
\hline \multicolumn{5}{|c|}{$\mathrm{s}_{1}=\mathrm{s}_{2}=0 \mathrm{~m}^{2}$} & \multicolumn{4}{|c|}{$\mathrm{s}_{1}=\mathrm{s}_{2}=10 \mathrm{~m}^{2}$} & \multicolumn{4}{|c|}{$\mathrm{s}_{1}=\mathrm{s}_{2}=20 \mathrm{~m}^{2}$} \\
\hline Case & $\mathbf{t}_{\mathbf{r}}[\mathrm{sec}]$ & $\mathbf{t}_{\mathbf{s}}[\mathrm{sec}]$ & $\mathbf{T}_{\mathbf{s r}}[\mathrm{K}]$ & $\mathbf{T}_{\mathbf{s s}}[\mathrm{K}]$ & $\mathbf{t}_{\mathbf{r}}[\mathrm{sec}]$ & $\mathbf{Q}_{\mathbf{s}}\left[\mathrm{m}^{3} / \mathrm{s}\right]$ & $\mathbf{H}_{\mathbf{a}}[\mathrm{m}]$ & $\mathbf{T}_{\mathbf{s r}}[\mathrm{K}]$ & $\mathbf{t}_{\mathbf{r}}[\mathrm{sec}]$ & $\mathbf{Q}_{\mathbf{s}}\left[\mathrm{m}^{3} / \mathrm{s}\right]$ & $\mathbf{H}_{\mathbf{a}}[\mathrm{m}]$ & $\mathbf{T}_{\mathbf{s r}}[\mathrm{K}]$ \\
\hline $\mathrm{A}$ & 93 & 71 & 419 & 363 & 201 & 28.0 & 5.57 & 395 & 168 & 38.52 & 7.41 & 374 \\
\hline $\mathrm{B}_{2}$ & 129 & 99 & 457 & 395 & 274 & 26.62 & 5.49 & 382 & 191 & 37.42 & 7.35 & 367 \\
\hline $\mathrm{B}_{3}$ & 159 & 121 & 481 & 416 & 268 & 25.5 & 5.41 & 373 & 198 & 36.5 & 7.29 & 361 \\
\hline $\mathrm{C}$ & 106 & 87 & 336 & 320 & 261 & 44 & 8.7 & 343 & 214 & 69.9 & 12.15 & 330 \\
\hline $\mathrm{D}_{1}$ & 361 & 246 & 560 & 487 & 670 & 21.12 & 5.03 & 342 & 531 & 32.14 & 6.98 & 339 \\
\hline
\end{tabular}

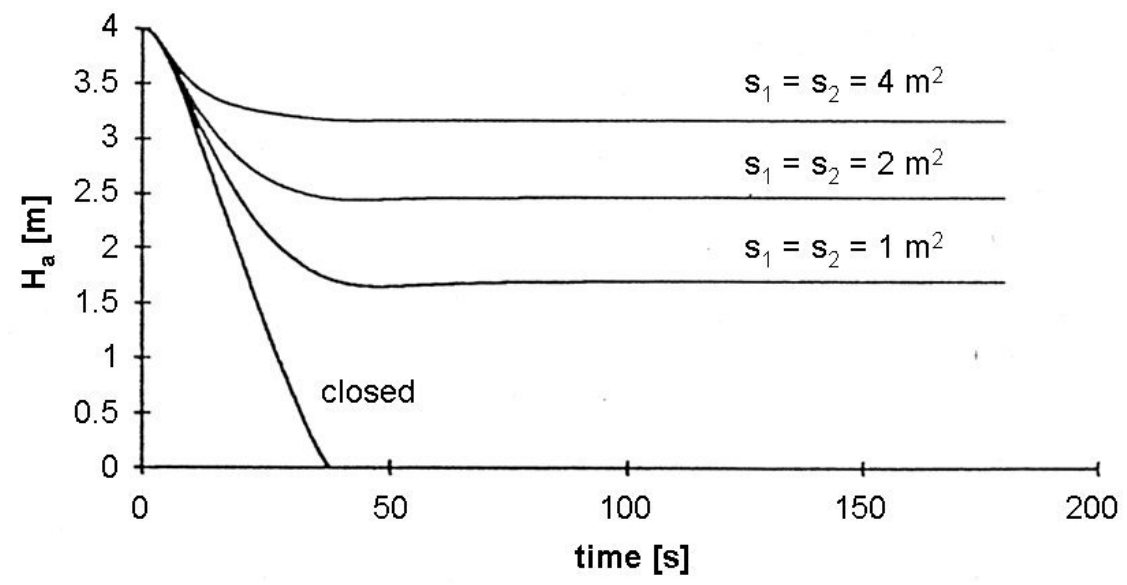

Fig. (3). Height of the smoke layer as a function of time in a typical residential building, for different areas of the inlet and outlet openings in the building envelope. 


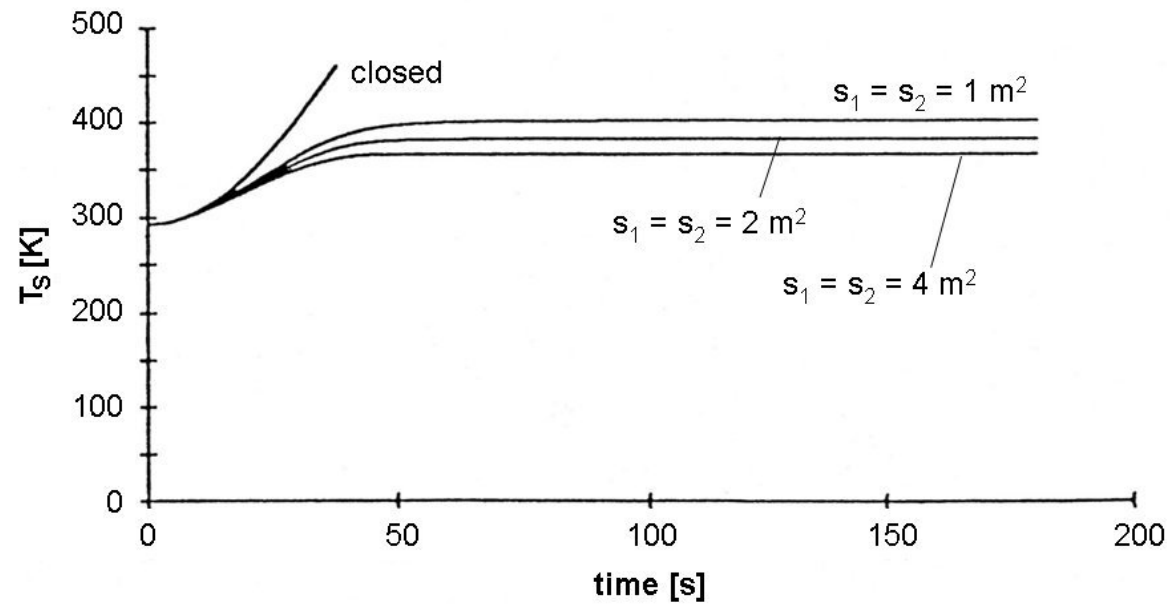

Fig. (4). Temporal evolution of the smoke temperature in a typical residential building, for different areas of the inlet and outlet openings in the building envelope.

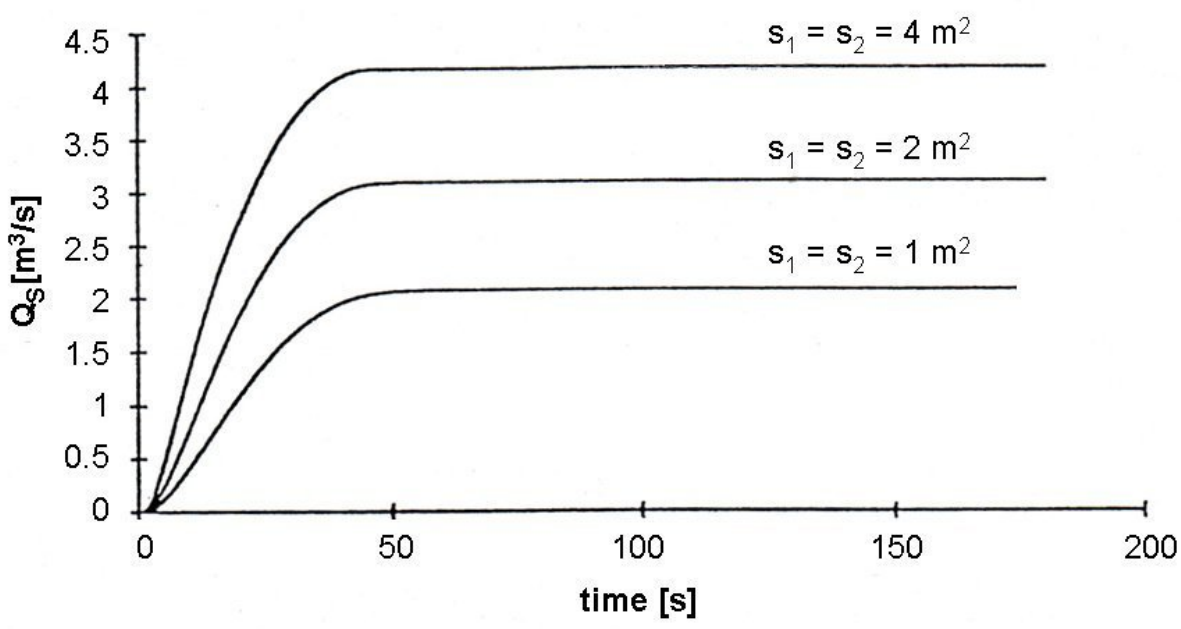

Fig. (5). Temporal evolution of the smoke volumetric flow rate from a typical residential building, for different areas of the inlet and outlet openings in the building envelope.

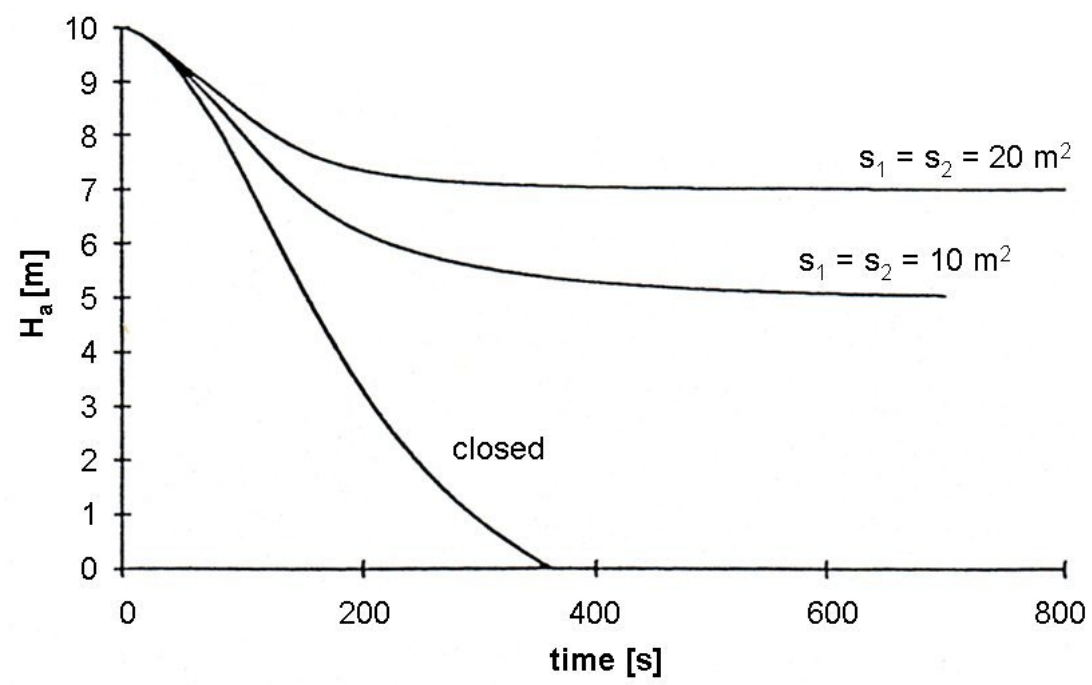

Fig. (6). Height of the smoke layer as a function of time in a typical industrial building, for different areas of the inlet and outlet openings in the buildingt envelope. 


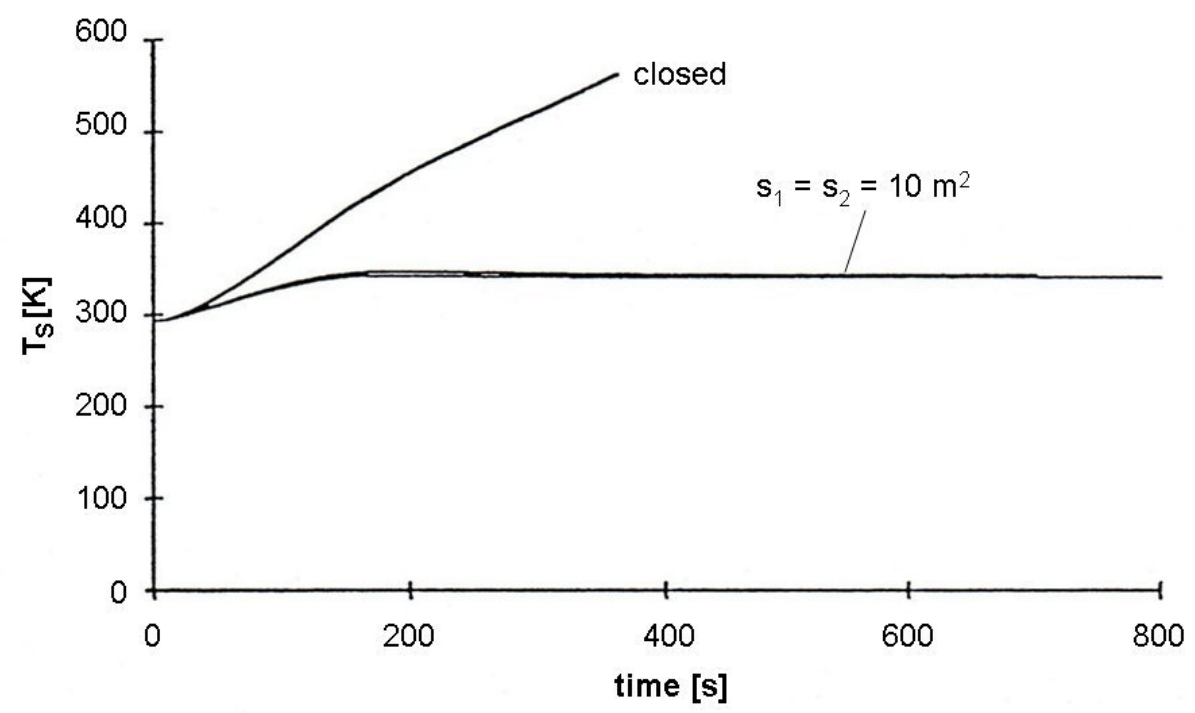

Fig. (7). Temporal evolution of the smoke temperature in a typical industrial building, for different areas of the inlet and outlet openings in the building envelope.

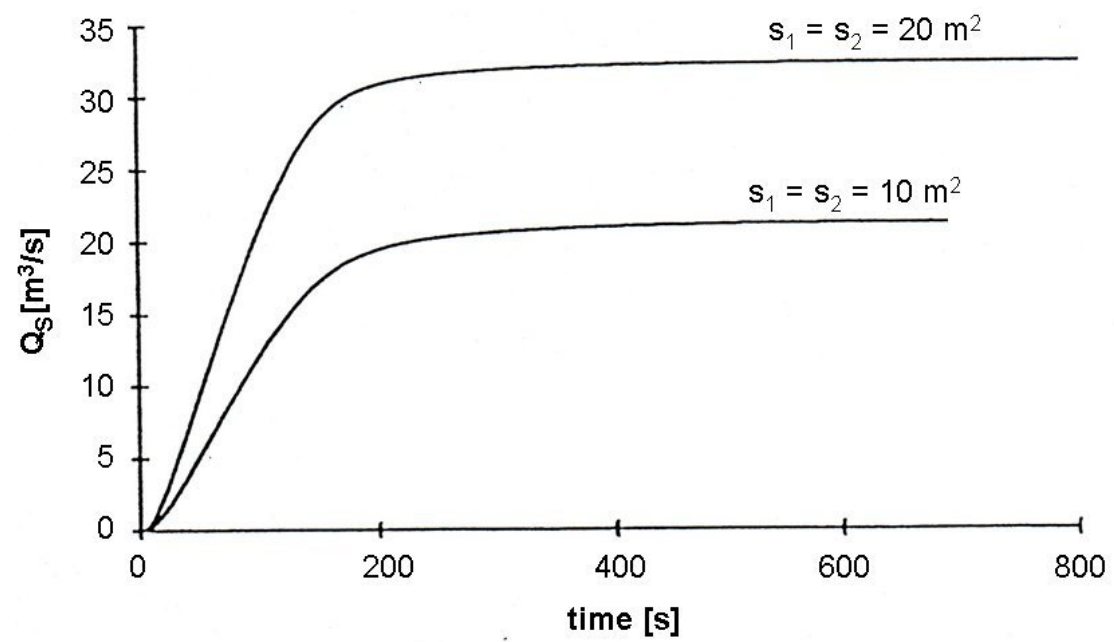

Fig. (8). Temporal evolution of the smoke volumetric flow rate from a typical industrial building, for different areas of the inlet and outlet openings in the building envelope.

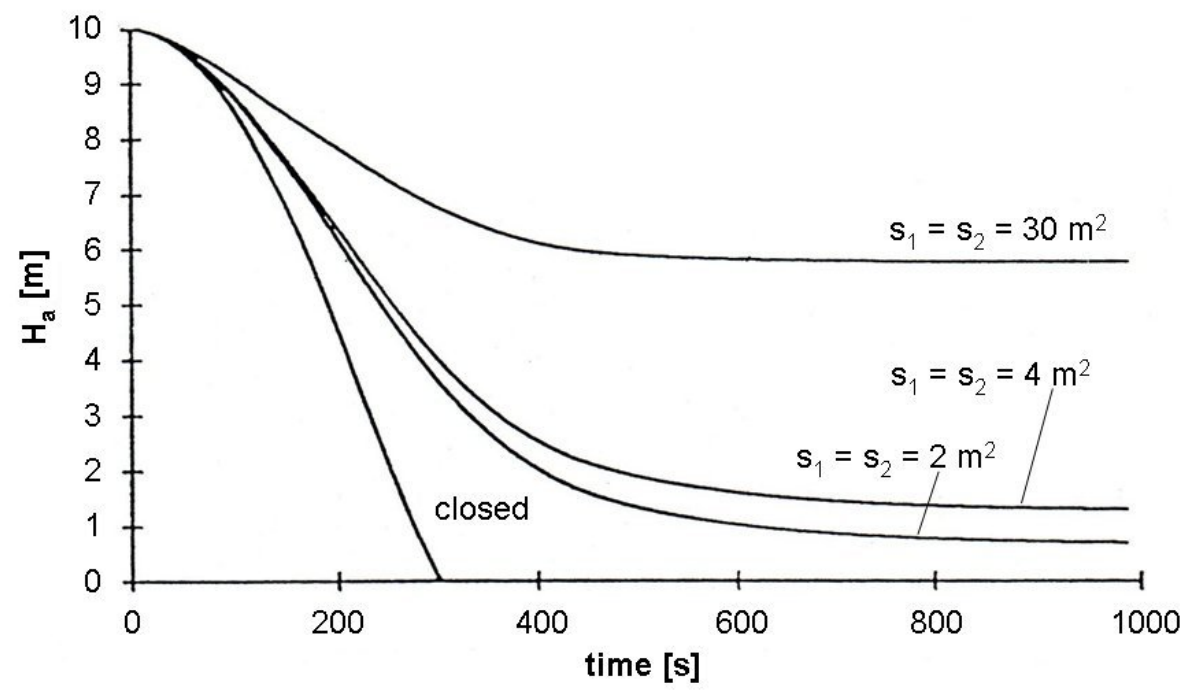

Fig. (9). Height of the smoke layer as a function of time in a tunnel, for different areas of the smoke outlet. 


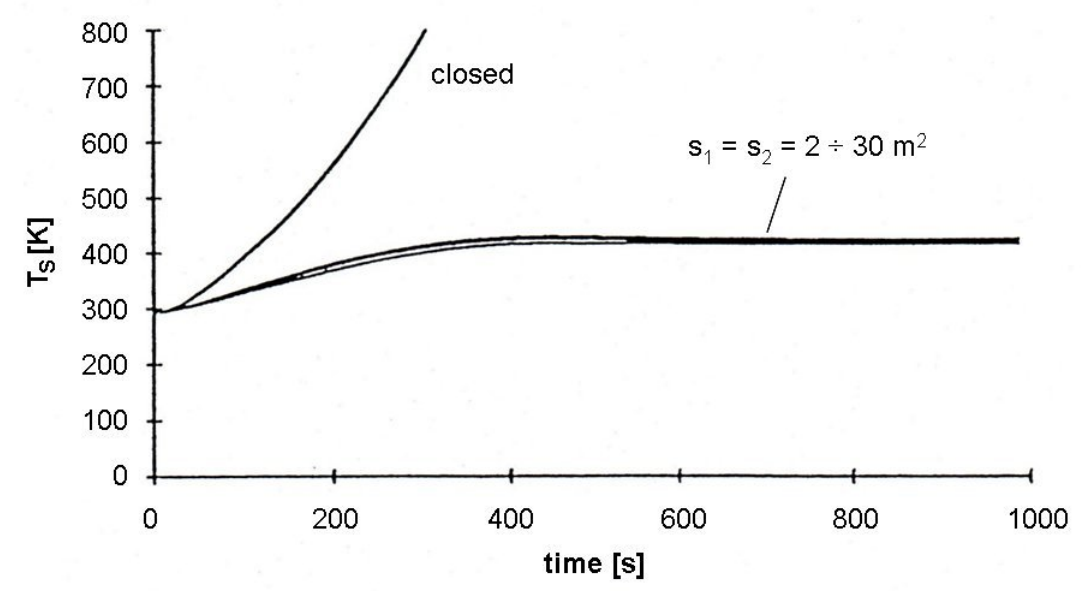

Fig. (10). Temporal evolution of the smoke temperature in a tunnel, for different areas of the smoke outlet.

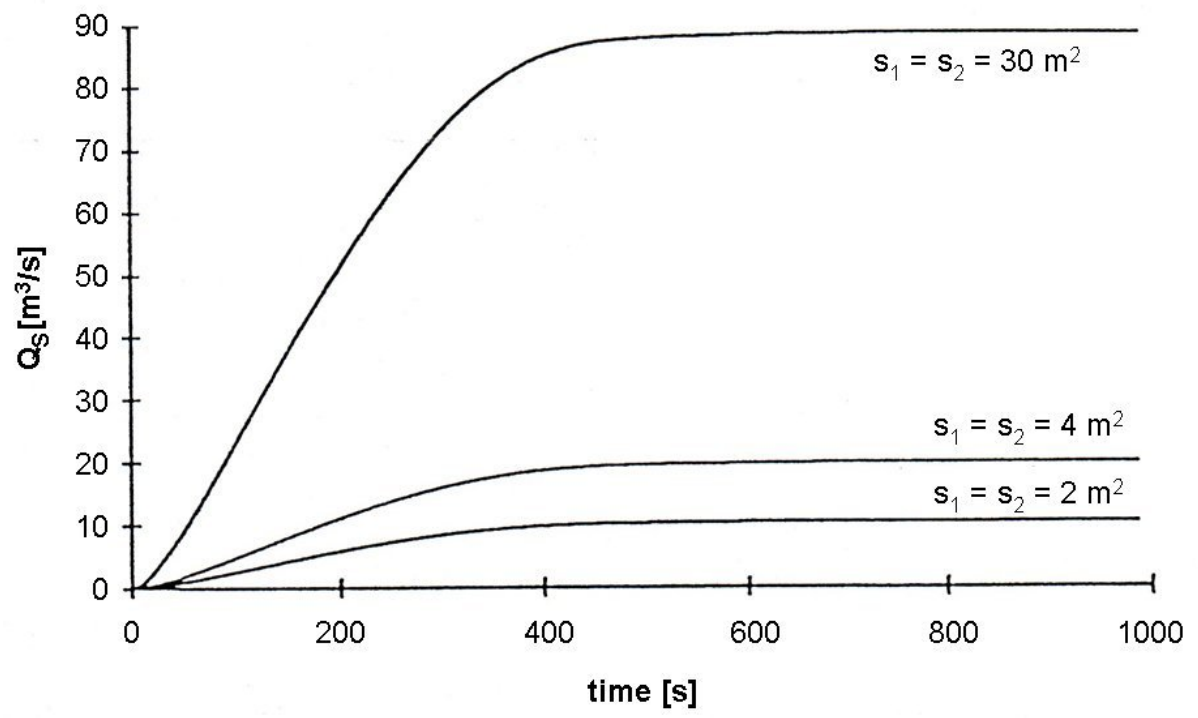

Fig. (11). Temporal evolution of the smoke volumetric flow rate from a tunnel, for different areas of the smoke outlet.

In typical residential buildings (Figs. 3-5), smoke fills the compartment completely in less than one minute in the absence of ventilation. On the other hand, if there are openings the height of the smoke layer attains a constant value (which of course depends strongly on the openings area), leaving a layer of fresh air in the bottom of the room. In these conditions, the smoke temperature reaches a constant value as well, but the dependence on the openings area is weaker.

In industrial buildings (Figs. 6-8) the situation is less critical: in fact, the large doors and windows typical of these buildings cause the smoke layer to reach a height that allows evacuation of people, and its temperature does not exceed significantly the ambient value. In the case of no openings, the time required to fill the compartment is of the order of 6 minutes. Finally, in the case of tunnels (Figs. 9-11) the model predictions indicate that the smoke layer reaches an asymptotic temperature of about $400 \mathrm{~K}$ independently of the size of openings (i.e., of the tunnel cross-sectional area), as shown in Fig. 10. The time evolution of the smoke layer height (Fig. 9) suggests that, depending on the crosssectional area of the tunnel, the survival time in case of fire can be shorter than 10 minutes. Because this model does not take into account possible instabilities of the smoke layer with consequent mixing with the underlying layer of fresh air, the values of the survival time could be shorter in practice.

As a concluding remark, it is important to observe how the shape factor plays a fundamental role in determining the smoke layer evolution when one of the geometric parameters is fixed. For example, Fig. (12) shows that for a given volume, compartment of small shape factors will take a longer time to be completely filled with smoke. Similarly, in compartments of a given height the smoke layer will take a longer time to reach the floor in case of smaller shape factors, as shown in Fig. (13).

\section{CONCLUSIONS}

The standard conservation equation of mass, momentum and energy, combined with a suitable set of phenomenologi- 


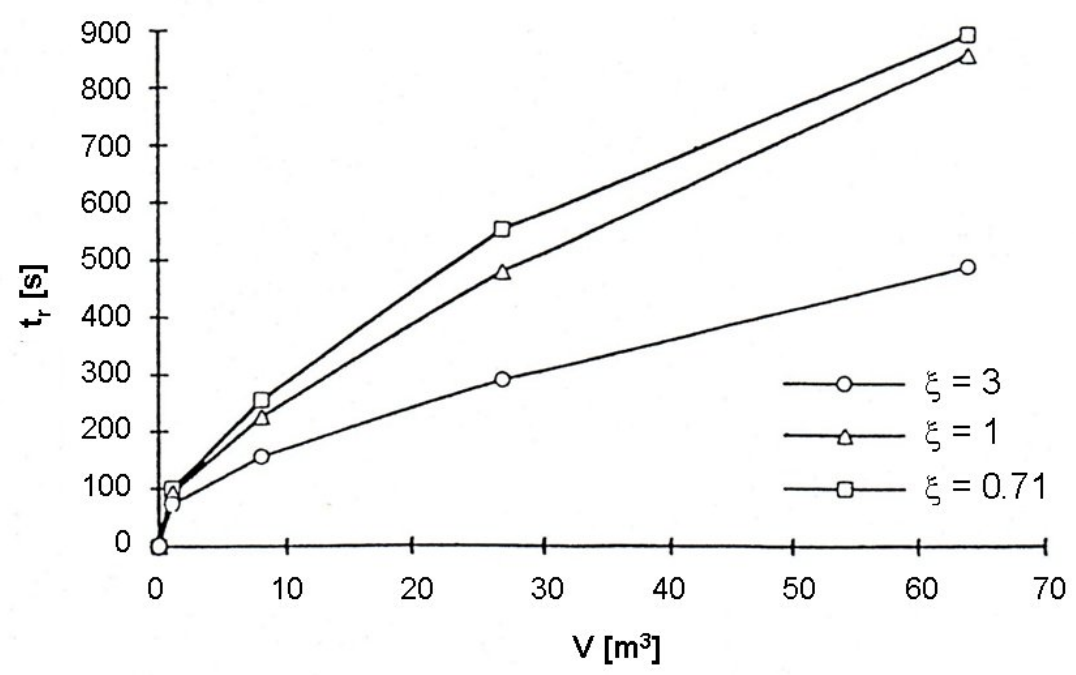

Fig. (12). Variation of the time required to fill the compartment as a function of the compartment volume, for different shape factors.

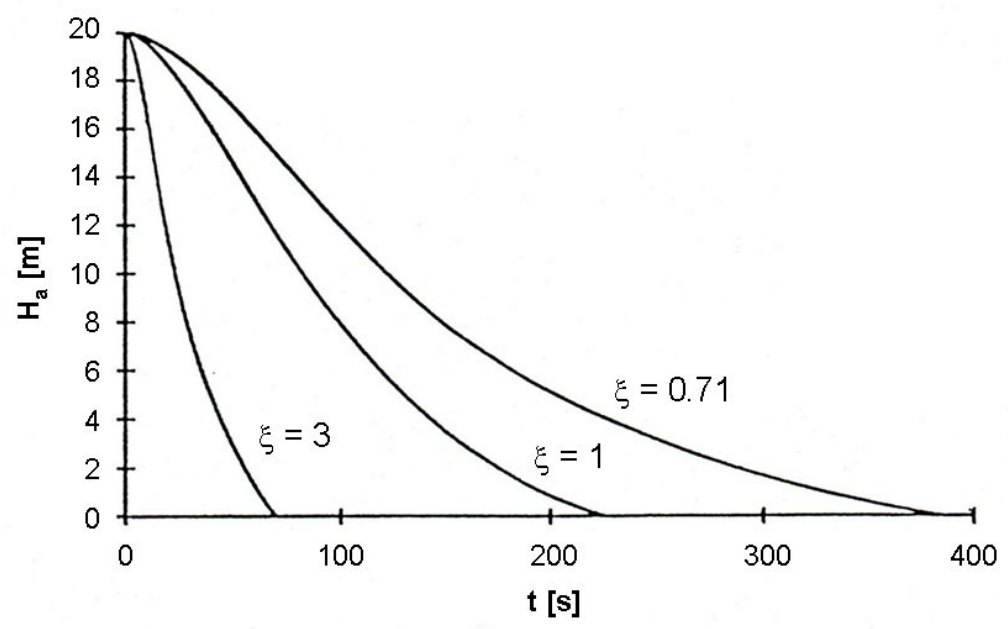

Fig. (13). Temporal evolution of the smoke layer thickness in compartments of a given height, for different shape factors.

cal closure relationships, allow the construction of a mathematical model of the smoke layer temporal evolution in compartment fires of different geometries. In particular, the proposed model allows one to simulate the temporal evolution of the smoke layer and its average temperature, to estimate the volumetric flow rates of the smoke through the openings on the building envelope, and to make an assessment of the environmental impact of the fire in the surrounding area.

The results can be used to design buildings with improved fire safety features, to dimension correctly ventilation systems, and to establish guidelines and criteria for emergency procedures. Of course, the model results should be always interpreted keeping in mind the assumptions underlying the model construction (for example, a stable interface between the smoke and the fresh air layers).

Whilst a thorough validation of the model is not possible to date because of the lack of experimental data covering a statistically relevant range of geometric and thermo-fluid dynamic parameters, some interesting comparisons might be possible with the results of some recent full-scale experiments [15].

\section{REFERENCES}

[1] J. H. Klote, A computer model of smoke movement by air conditioning systems (SMACS), Report NBSIR 87-3657, U.S. Department of Commerce, Gaithersburg, MD 20899, 1987.

[2] R. W. Bukowski, R. D. Peacock, W. W. Jones, C. L. Forney, Fire Hazard Assessment Method, Volumes I, II and III, NIST Handbook 146, 1989.

[3] R.W. Portier, P. A. Renke, W.W. Jones, R.D. Peacock, A user's guide for CFAST version 1.6, NISTIR 4985, U.S. Department of Commerce, Gaithersburg, MD 20899, 1992.

[4] E. Cafaro, G. V. Fracastoro, Il metodo della termofluidodinamica numerica nello studio dei moti dell'aria all'interno degli edifici, Condizionamento dell'Aria, vol. 36, 1992, pp. 1696-1716.

[5] E. Cafaro, P. Balocco, F. Potenza, MPLM Fire Detection and Suppression, Proc. $23^{r d}$ SAE International Conference on Environmental Systems, Colorado Springs, CO, July 12-15, 1993.

[6] E. E. Zukoski, "Development of a stratified ceiling layer in early stages of a closed-room fire", Fire and Materials, vol. 2, pp. 54-61, 1978.

[7] L. Y. Cooper, "A concept for estimating available safe egress time in fires", Fire Saf. J., vol. 5, pp. 135-144, 1983.

[8] G. Heskestad, "Virtual origins of fire plumes", Fire Saf. J., vol. 5, pp. 109-114, 1983. 
[9] G. Heskestad,"Engineering relations for fire plumes”, Fire Saf. J., vol. 7, pp. 25-32, 1984

[10] G. Heskestad, "Smoke movement and venting", Fire Saf. J., vol. 11, 1986, pp. 77-83.

[11] B. J. Wiekema, "Methods for the calculation of the physical effects of the escape of dangerous material (liquid and gases)", TNO, The Netherlands, 1979.

[12] P. L. Hinkley, "Smoke and Heat Venting, in SFPE Handbook of Fire Protection Engineering", P. Di Nenno, Ed., Quincy MA: Na- tional Fire Protection Association, press, Section 2, 1988, pp. 2344.

[13] G. A. Briggs, Plume Rise, AEC Critical Review Series, TID25075, 1969.

[14] D.B. Turner, Workbook of atmospheric dispersion estimates: an introduction to dispersion modelling, $2^{\text {nd }}$ ed., CRC Press, USA, 1994.

[15] G. Rein, C. Abecassis-Empis, R. Carvel Eds., The Dalmarnock fire tests: experiments and modelling, UK: University of Edinburgh Press, 2007.

Received: December 09, 2009

Revised: February 08, 2010

Accepted: February 11, 2010

(C) Bennardo and Inzaghi; Licensee Bentham Open.

This is an open access article licensed under the terms of the Creative Commons Attribution Non-Commercial License

(http://creativecommons.org/licenses/by-nc/3.0/) which permits unrestricted, non-commercial use, distribution and reproduction in any medium, provided the work is properly cited. 